\title{
Alelopatia de Leucaena leucocephala e Hovenia dulcis em mudas de Mimosa bimucronata e Peltophorum dubium
}

\author{
Allelopathy of Leucaena leucocephala and Hovenia dulcis on Mimosa bimucronata \\ and Peltophorum dubium seedlings
}

\author{
Vandjore de Mattos Ribeiro $\left.{ }^{*}{ }^{*}\right)$ \\ Andrea Maria Teixeira Fortes ${ }^{2}$ \\ Jaqueline Malagutti Corsato ${ }^{3}$ \\ Rennan Oliveira Meira ${ }^{4}$ \\ Lorena Camargo de Mendonça ${ }^{5}$ \\ Flávia Danieli Rech Cassol ${ }^{6}$
}

\section{Resumo}

As plantas, mesmo após a senescência, mantêm em seus tecidos substâncias alelopáticas que podem ser lixiviadas para o solo através da decomposição da serapilheira. Para simular os efeitos recorrentes da decomposição de material vegetal sobre o desenvolvimento de espécies vegetais existentes nos ecossistemas de florestas, este trabalho teve por objetivo avaliar o efeito dos extratos em pó obtido das folhas das espécies Leucaena leucocephala e Hovenia dulcis em plantas de Mimosa bimucronata e Peltophorum dubium. Para isso, foram calculados os valores de aporte de serapilheira depositados nos diferentes meses do ano. Foi avaliada a altura, diâmetro do caule, número de folhas e massa seca da raiz e parte aérea. Não foi observada diferença significativa em todas as variáveis de crescimento analisadas para Mimosa bimucronata. Já em relação ao Peltophorum dubium, ambos os extratos promoveram aumento na altura de plantas nos dois últimos meses de avaliação.

Palavras-Chave: Efeito alelopático, serapilheira, metabólitos secundários.

1 Me.; Conservação e Manejo de Recursos Naturais; Universidade Estadual do Oeste do Paraná, UNIOESTE, Brasil; Servidora pública municipal; Endereço: Rua Jaraguá, 406, Bairro Periolo, CEP 85817- 130, Cascavel,PR - Brasil; E-mail: vandm_@hotmail.com $\left(^{*}\right)$ Autor para correspondências

2 Dra.; Ciências Biológicas (Botânica); Universidade Estadual Paulista Júlio de Mesquita Filho, UNESP, Brasil; Professora da Universidade Estadual do Oeste do Paraná; Endereço: Universidade Estadual do Oeste do Paraná, Centro de Ciências Biológicas e da Saúde, Colegiado de Ciências Biológicas. Rua Universitaria, 2069, Jardim Universitario. CEP: 85814110 - Cascavel, PR- Brasil; E-mail: amtfortes@hotmail.com

3 Dra; Ciências Biológicas (Botânica); Universidade Estadual Paulista Júlio de Mesquita Filho, UNESP, Brasil; Professora Colaboradora (Botânica) na Universidade Estadual do Oeste do Paraná, UNIOESTE Campus Cascavel-Pr; Endereço: Universidade Estadual do Oeste do Paraná (UNIOESTE), Rua Universitária, 1619, Jardim Universitário, CEP: 85.819110, Cascavel-PR, Brasil; E-mail: jaque_corsato@hotmail.com

4 Doutorando; Botânica. Universidade de Brasília, UnB, Brasil; Atua na linha de pesquisa: Cultura de tecidos e transformação genética de plantas, em parceria com a Embrapa Recursos Genéticos e Biotecnologia (CENARGEN); Endereço: Secretaria da Coordenação de Pós-Graduação em Botânica - Instituto de Ciências Biológicas (IB), Campus Darcy Ribeiro, Departamento de Botânica, CEP 70919-970, Brasília-DF, Brasil; E-mail: rennan. meira@hotmail.com

5 Me.; Engenharia Agrícola; Universidade Estadual do Oeste do Paraná,UNIOESTE, Brasil; E-mail: lorena.cm @hotmail. com

6 Dra.; Engenharia Agrícola; Universidade Estadual do Oeste do Paraná, UNIOESTE, Brasil; Professora no Ceebja Professora Joaquina Mattos Branco, Endereço: Av. Rocha Pombo, 1936 - Região do Lago, Cascavel - PR, Brasil, CEP 85816-540, E-mail: fdrcassol@hotmail.com

\begin{tabular}{llllll}
\hline Ambiência & Guarapuava (PR) & v.14n.3 & p.649-661 & Set/Dez 2018 & ISSN $1808-0251$
\end{tabular}




\section{Abstract}

The plants even after senescence keep in their tissues allelopathic substances that can be leached to the soil through the decomposition of the litter. To simulate the recurrent effects of decomposition of plant material on the development of plant species existing in forest ecosystems, this study aimed to evaluate the effect of the powder extracts obtained from the leaves of the species Leucaena leucocephala and Hovenia dulcis in Mimosa bimucronata and Peltophorum dubium plants. To do this, the values were calculated from amount of leaf litter deposited in different months of the year. It was evaluated the height, stem diameter, number of leaves and dry weight of root and shoot. There was no significant difference in all growth variables analyzed for Mimosa bimucronata. Already in relation to Peltophorum dubium, both extracts promoted increased plant height in the last two months.

Key words: Allelopathic effect, leaf litter, secondary metabolites.

\section{Introdução}

A Floresta Estacional Semidecidual (FES) constitui uma vegetação pertencente ao bioma da Mata Atlântica. Há aproximadamente um século, a Floresta Estacional Semidecidual recobria praticamente a metade dos estados de São Paulo e Paraná. Esta subfisionomia da Floresta Atlântica se tornou a mais ameaçada, decorrente de seu desflorestamento quase completo e muito rápido (GUBERT-FILHO, 2010). No Paraná, a situação da Mata Atlântica é crítica, restando poucos remanescentes, principalmente da Floresta com Araucárias e da Floresta Estacional Semidecidual (FERRETTI; BORGES; BRITEZ, 2006), sendo que a FES corresponde a apenas 3\% da área original remanescente (CAMPOS; SILVEIRA-FILHO, 2010), representada por fragmentos florestais de diferentes tamanhos, dispostos irregularmente ao longo da área de distribuição da formação (SOS MATA ATLÂNTICA /INPE/ISA 1998).

Com a diminuição dos ambientes florestais, tiveram início os incentivos ao reflorestamento, visando restabelecer as comunidades naturais de áreas que sofreram degradação. Na década de 60, as áreas desmatadas da FES da região oeste do Estado do Paraná passaram por este processo. De acordo com Moretto (2009), a falta de descrição das espécies a serem reflorestadas, no Código Florestal de 1965, deu abertura para uma série de irregularidades no processo de liberação de créditos para o reflorestamento. O Código não se posicionava como o replantio deveria ser realizado, restringindo-se apenas ao plantio de árvores, sem critérios ecológicos para a escolha das espécies que seriam utilizadas. Assim, Bellotto, Gandolfi, e Rodrigues (2009) relatam que as práticas de recuperação passaram a introduzir espécies exóticas devido às características de rápido crescimento, fácil cultivo e adaptação a áreas degradadas.

Em alguns fragmentos da Floresta Estacional Semidecidual do estado do Paraná, observase a presença de espécies exóticas, destacando-se a Leucaena leucocephala e Hovenia dulcis (VALAITES, 2011; GRIS, 2012; TOSCAN et al., 2014), espécies do presente estudo.

As espécies $H$. dulcis e L. leucocephala apresentam grande número de ocorrência nos hábitats naturais mais difundidas no Brasil, como florestas subtropicais, as quais podem competir com espécies nativas por espaço, luz e nutrientes, e, dessa forma, reduzir a disponibilidade destes recursos (ZENNI; ZILLER, 2011). Uma vez que uma espécie coloniza uma área que foi 
perturbada, ela permanece por muitos anos, competindo lentamente com a vegetação nativa, vindo a formar novas populações, de acordo, com a ocorrência de novas perturbações (ROSA, 2006). A adaptabilidade dessas espécies se deve à alta taxa de crescimento, alta produção de sementes pequenas e de fácil dispersão, alta longevidade das sementes no solo, alta taxa de germinação, maturação precoce das plantas já estabelecidas, floração e frutificação mais prolongadas, alto potencial reprodutivo por brotação, pioneirismo e alelopatia (GENOVESI, 2005).

A M. bimucronata, conhecida popularmente como maricá, é considerada espécie típica da Floresta Atlântica, com ampla distribuição nesse bioma (LORENZI, 2008). Trata-se de uma espécie arbórea com 3 a $10 \mathrm{~m}$ de altura, podendo atingir até $15 \mathrm{~m}$ de altura na idade adulta, muito ramificada e aculeada, possuindo característica de semicaducifolia a caducifólia (CARVALHO, 2004). Comumente encontrada em abundância em várzeas brejosas ao longo dos rios, banhados e outras depressões dos terrenos onde, não raro, forma densas associações, sendo também frequente em formações secundárias situadas em encostas, sobretudo em solos rochosos, com declividade pouco acentuada (LORENZI, 2000).

Sendo espécie pioneira, M. bimucronata apresenta grande importância na recuperação de áreas degradadas, nas quais é indicadora do estágio inicial de regeneração (BRASIL, 1994).

Peltophorum dubium, conhecida popularmente por canafístula, é uma espécie arbórea, secundária inicial com característica de pioneira (DURIGAN; NOGUEIRA, 1990). A espécie é encontrada em todo o domínio da floresta estacional semidecidual ocupando o estrato dominante do dossel em florestas primárias (PIROLI et al., 2005). Por ser uma planta rústica e de rápido crescimento, é comumente encontrada colonizando pastagens, ocupando clareiras e bordas de matas, sendo também utilizada para a composição de reflorestamentos mistos de áreas degradadas e de preservação permanente (DONADIO; DEMATTÊ, 2000).

A alelopatia é definida como o efeito inibitório ou benéfico, direto ou indireto, de uma planta sobre outra, via produção de compostos químicos que são liberados no ambiente (SOUZA et al., 2006). A partir das folhas, raízes e serapilheira em decomposição, os vegetais possibilitam a liberação de metabólitos primários e secundários no ambiente. A alelopatia caracteriza-se pela capacidade das plantas liberarem no ambiente por meio da volatilização, lixiviação, exsudação das raízes e decomposição de resíduos vegetais substâncias denominadas aleloquímicos que podem influenciar no crescimento e no desenvolvimento de outras espécies (SONEGO et al., 2012).

A liberação dos compostos de restos vegetais ocorre pela decomposição de partes aéreas ou subterrâneas depositadas sobre o solo, como serapilheira das matas, em que a perda da integridade de membranas celulares permite a liberação de um grande número de compostos potencialmente aleloquímicos. A sucessão da vegetação de uma determinada área pode ser condicionada a preexistência de substâncias químicas liberadas pela população de plantas anteriores e seu tempo de permanência no local (BRASS, 2009).

Informações sobre as espécies adequadas para revegetação são importantes para estudos de repovoamento de habitats, considerando seus aspectos ecológicos, de forma a garantir a conservação e correto manejo da área para proteger a biodiversidade nativa de uma determinada região. Todas estas características expostas, somado à capacidade destas espécies em formar populações densas e dominantes torna necessária a investigação do potencial alelopático de cada espécie, sendo esta, uma possível estratégia que contribui no estabelecimento dessas populações. 
Assim, o objetivo deste trabalho foi avaliar o efeito dos extratos em pó obtido das folhas das espécies de $L$. leucocephala e $H$. dulcis sobre o desenvolvimento de plantas de $M$. bimucronata e P. dubium.

\section{Material e Métodos}

O experimento foi conduzido em casa de vegetação da Universidade Estadual do Oeste do Paraná - campus de Cascavel - (UNIOESTE), localizado no munícipio de Cascavel, Paraná, Brasil, no período de novembro de 2013 a abril de 2014.

O delineamento experimental foi em blocos casualizados, distribuídos em três tratamentos, quatro repetições e oito mudas por repetição. Os dados foram submetidos à análise de variância e as médias comparadas pelo teste Tukey a $1 \%$ de probabilidade utilizando o programa estatístico Assistat 7.7 Beta.

As folhas de L. leucocephala e $H$. dulcis utilizadas para produção do extrato em pó foram coletadas diretamente das árvores, já em estádio de senescência, na Faixa de Proteção do Reservatório de Itaipu, na região Oeste do Paraná, localizado entre as coordenadas 2540'23.03" $\mathrm{S}$ e $54^{\circ} 39^{\prime} 46.50^{\prime \prime} \mathrm{O}$.

De acordo com o Iapar (2014), o clima da região é subtropical (Cfa), com temperatura média inferior, a $18^{\circ} \mathrm{C}$ no mês mais frio e temperatura média acima de $22^{\circ} \mathrm{C}$ no mês mais quente, com tendência de concentração das chuvas nos meses de verão, contudo sem estação seca definida.

A formação vegetacional é representada por Floresta Estacional Semidecidual, caracterizada por apresentar duas estações bem definidas, uma chuvosa e outra seca. Tal característica climática é um dos fatores determinantes de uma forte estacionalidade foliar dos elementos arbóreos dominantes, como resposta ao período de deficiência hídrica, ou à queda de temperatura nos meses mais frios. (FERRETTI; BORGES; BRITEZ, 2006).

A coleta das folhas ocorreu no mês de setembro de 2014, sendo que a média das temperaturas neste período variou entre $24^{\circ} \mathrm{C} \mathrm{e} 26^{\circ} \mathrm{C}$. A precipitação total do mês foi de $24,4 \mathrm{~mm}$ (SEAB, 2014).

Foram realizadas exsicatas dos materiais coletados, sendo estas depositadas no herbário da Universidade Estadual do Oeste do Paraná - HUOP, sob os números de identificação 1463 e 1464.

As folhas de L. leucocephala e $H$. dulcis foram secas em estufa de circulação de ar, a $40^{\circ} \mathrm{C}$, até atingir seu peso constante. Após esta secagem, as folhas foram trituradas em moinho de facas tipo Willey, com peneira malha 30, a fim de reduzir o material vegetal a fragmentos, de forma a acelerar o processo de decomposição. As amostras foram acondicionadas em frascos de vidro devidamente identificados, protegidos de umidade, a temperatura ambiente, até sua utilização.

Foram utilizados vasos de polietileno com capacidade de $5 \mathrm{~L}$ e como substrato, foi utilizado o Latossolo Vermelho, o qual foi devidamente corrigido com calcário dolomítico. Mudas de aproximadamente cinco meses de idade, de Mimosa bimucronata e Peltophorum dubium, foram doadas pelo Instituto Ambiental do Paraná - IAP, as quais foram transplantadas para os vasos, para o estabelecimento dos tratamentos.

O material vegetal das espécies doadoras foi depositado mensalmente no solo dos vasos com o propósito de simular o que acontece naturalmente na natureza, com a decomposição da serapilheira. Para tal, a quantidade de material vegetal depositada sobre as mudas foi calculada a partir da média de produção de serapilheira observada. Para L. leucocephala foi observado por Bertalot et al. (2004) valor correspondente a $1388,8 \mathrm{~kg} \mathrm{ha}^{-1} \mathrm{ano}^{-1}$. Para $H$. dulcis, não foi encontrado valores referentes a deposição individual de serapilheira desta espécie, logo, adotou-se a média de produção de serapilheira da área em que foram coletadas as folhas das espécies do presente estudo, obtendo-se a média de 9304,97 $\mathrm{kg} \mathrm{ha}^{-1}$ ano $^{-1}$ (TOSCAN, 2013). Após adaptação para área da 
unidade experimental e do tempo de experimentação, levando-se em conta que a produção de serapilheira varia sob diferentes períodos sazonais, foi definido o valor de $0,4 \mathrm{~g}$ de material vegetal

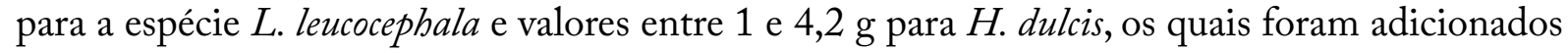
mensalmente aos vasos com as mudas das espécies receptoras, $M$. bimucronata e $P$. dubium.

O experimento foi observado durante o período de seis meses, com avaliação mensal. Os parâmetros analisados foram: altura da planta $(\mathrm{cm})$, sendo esta variável obtida pela distância do colo da planta e a extremidade das últimas axilas foliares, diâmetro do caule $(\mathrm{cm})$, realizada por meio de paquímetro, número de folhas, e ao final do experimento, a massa seca do sistema radicular e parte aérea, através da secagem em estufa de circulação forçada a $70^{\circ} \mathrm{C}$ durante 72 horas.

\section{Resultado e Discussão}

Não foi observado efeito significativo do extrato em pó de $L$. leucocephala e $H$. dulcis para altura, diâmetro do caule e número de folhas de M. bimucronata, (Tabela 1) contudo, quando observados estes parâmetros ao longo dos seis meses de experimento, foi possível observar aumento gradual na altura das plantas, no diâmetro do caule assim como no número de folhas de $M$. bimucronata. Provavelmente isto ocorreu porque as plantas estavam em fase ativa de crescimento, não sendo possível, portanto, associar tais aumentos como resultado de efeito alelopático.

Tabela 1 - Altura, diâmetro do caule e número de folhas de Mimosa bimucronata

DC. Kuntze sob efeito do extrato em pó de Leucaena leucocephala (Lam) R. de Wit e Hovenia dulcis Thunberg. Cascavel-PR, 2015.

\begin{tabular}{lcccccc}
\hline \multirow{2}{*}{ Tratamentos } & Nov & Dez & Jan & Fev & Março & Abril \\
\cline { 2 - 7 } & \multicolumn{7}{c}{ Altura(cm) } \\
\hline Testemunha & 42,62 & 48,04 & 57,90 & 72,63 & 79,42 & 83,28 \\
L.leucocephala & 40,56 & 45,74 & 58,38 & 74,80 & 81,94 & 84,96 \\
H. dulcis & 43,25 & 49,60 & 58,82 & 71,54 & 77,33 & 82,27 \\
\hline
\end{tabular}

$$
\mathrm{CV}(\mathrm{a})=13,86 \% \mathrm{CV}(\mathrm{b})=7,94 \%
$$

\section{Diâmetro do caule (cm)}

\begin{tabular}{lcccccc}
\hline Testemunha & 0,60 & 0,63 & 0,68 & 0,75 & 0,81 & 0,89 \\
L.leucocephala & 0,75 & 0,77 & 0,80 & 0,86 & 0,90 & 1,00 \\
H. dulcis & 0,61 & 0,67 & 0,68 & 0,77 & 0,80 & 0,88 \\
\hline
\end{tabular}

$$
\mathrm{CV}(\mathrm{a})=20,44 \% \mathrm{CV}(\mathrm{b})=7,99 \%
$$

Número de folhas

\begin{tabular}{lllllll}
\hline Testemunha & 20 & 50 & 82 & 136 & 135 & 126 \\
L.leucocephala & 21 & 58 & 91 & 134 & 128 & 113 \\
H. dulcis & 18 & 48 & 84 & 128 & 125 & 108 \\
\hline
\end{tabular}

$$
\mathrm{CV}(\mathrm{a})=33,26 \% \mathrm{CV}(\mathrm{b})=10,17 \%
$$

$C V(a)=$ Coeficiente de variação dos tratamentos. $C V(b)=$ Coeficiente de variação do tempo (meses). 
Quando analisada a massa seca das plantas de M. bimucronata (Tabela 2), notou-se que os extratos de ambas as espécies, L. leucocephala e $H$. dulcis, não influenciaram este parâmetro, concordando com Prates, Pires e Pereira Filho, (2003) que verificaram que aplicação de folhas de L. leucocephala na superfície do solo não trouxe diferenças significativas em relação a biomassa da raiz de Zea mays.

Parvin, Shapla e Amin (2011) realizaram estudo em que folhas secas de L. leucocephala foram incorporadas em vasos contendo Glycine max e Vigna radiata e relataram que o número de folhas, o diâmetro do caule e biomassa de parte aérea e raiz destas espécies foram parâmetros que sofreram pouca ou nenhuma interferência. Parepa, Schaffner e Bossdorf (2012) também não verificaram interferência de serapilheira de Fallopia $\times$ bohemica, uma espécie também invasora, considerada de extrema agressividade, em biomassa de plantas nativas, como Lolium perenne, Poa trivialis, Filipendula ulmaria, Geranium robertianum, Geum urbanum, Glechoma hederacea, Silene dioica, Symphytum officinale e Urtica dioica.

Tabela 2 - Massa seca da raiz e parte aérea de Mimosa bimucronata DC. Kuntze sob efeito do extrato em pó de Leucaena leucocephala (Lam) R. de Wit e Hovenia dulcis Thunberg. Cascavel-PR, 2015.

\begin{tabular}{ccc}
\hline Tratamentos & Massa seca de raiz $(\mathrm{g})$ & Massa seca de parte aérea $(\mathrm{g})$ \\
\cline { 1 - 3 } \cline { 3 - 3 } Testemunha & 16,58 & 12,77 \\
L.leucocephala & 17,27 & 12,36 \\
H. dulcis & 17,63 & 10,50 \\
CV $(\%)$ & 8,58 & 4,64 \\
\hline
\end{tabular}

Para mudas de $P$. dubium, em relação à altura, houve diferença significativa entre as mudas do tratamento testemunha e as mudas tratadas com o extrato em pó de L. leucocephala, durante o mês de fevereiro. Nos meses de março e abril ambos os extratos promoveram aumento significativo da altura, sendo que para a testemunha foram observados os menores valores para este parâmetro (Tabela 3). Tal resultado pode ter sido encontrado devido ao incremento de nutrientes disponíveis, uma vez que o crescimento e desenvolvimento das plantas são condicionados por fatores ambientais, como o suprimento nutricional (OLIVEIRA et al., 2010). As espécies $L$. leucocephala e $H$. dulcis possuem quantidades significativas de nitrogênio (BERTALOT et al., 2004; OLADOYE et al., 2008; SCHUMACHER et al., 2008), o qual pode ter sido absorvido pela $M$. bimucronata e pelo $P$. dubium através da serapilheira, considerando que este nutriente é amplamente reconhecido como fator chave no funcionamento dos ecossistemas terrestres, determinando o desempenho das plantas, sendo fundamental nos processos ecológicos, como a produtividade (SCHEER, 2008). 
Tabela 3 - Altura, Diâmetro do Caule e Número de Folhas de Peltophorum dubium (Spreng.) Taub. sob efeito do extrato em pó de Leucaena leucocephala (Lam) R. de Wit e Hovenia dulcis Thunberg. Cascavel-PR, 2015.

\begin{tabular}{ccccccc}
\hline \multirow{2}{*}{ Tratamentos } & Nov & Dez & Jan & Fev & Março & Abril \\
\cline { 2 - 7 } & \multicolumn{7}{c}{ Altura } \\
\hline Testemunha & $9,45 \mathrm{aE}$ & $12,87 \mathrm{aD}$ & $23,32 \mathrm{aC}$ & $31,82 \mathrm{bB}$ & $33,79 \mathrm{bA}$ & 34,69 \\
L.leucocephala & $9,21 \mathrm{aD}$ & $11,82 \mathrm{aD}$ & $22,96 \mathrm{aC}$ & $36,88 \mathrm{aB}$ & $38,52 \mathrm{aA}$ & 40,95 \\
H. dulcis & $9,21 \mathrm{aD}$ & $11,95 \mathrm{aD}$ & $25,34 \mathrm{aC}$ & $34,86 \mathrm{abB}$ & $41,33 \mathrm{aA}$ & 43,64 \\
\hline
\end{tabular}

$$
\mathrm{CV}(\mathrm{a})=19,80 \% ; \mathrm{CV}(\mathrm{b})=4,99 \%
$$

Diâmetro do caule

\begin{tabular}{ccccccc}
\hline Testemunha & 0,26 & 0,32 & 0,47 & 0,64 & 0,80 & 0,88 \\
L.leucocephala & 0,23 & 0,30 & 0,46 & 0,62 & 0,73 & 0,93 \\
H. dulcis & 0,25 & 0,30 & 0,46 & 0,64 & 0,75 & 0,93 \\
\hline \multicolumn{7}{c}{$\mathrm{CV}(\mathrm{a})=17,92 \% ; \mathrm{CV}(\mathrm{b})=11,77 \%$}
\end{tabular}

Número de folhas

\begin{tabular}{ccccccc}
\hline Testemunha & 6 & 8 & 13 & 14 & 10 & 8 \\
L.leucocephala & 5 & 7 & 13 & 14 & 10 & 10 \\
H.dulcis & 5 & 7 & 13 & 14 & 10 & 9 \\
\hline
\end{tabular}

$\mathrm{CV}(\mathrm{a})=33,26 \% ; \mathrm{CV}(\mathrm{b})=10,17 \%$

Médias seguidas pela mesma letra minúscula na coluna e maiúscula na linha não diferem estatisticamente entre si pelo Teste de Tukey a $1 \%$ de probabilidade. CV (a) = Coeficiente de variação dos tratamentos. CV $(b)=$ Coeficiente de variação do tempo (meses).

De acordo com Havlin et al. (2005), a ocorrência de maiores taxas de assimilação e absorção do nutriente nitrogênio pelas plantas depende do estádio fenológico, ocorrendo principalmente na fase ativa de crescimento, sendo mais pronunciada em raízes jovens.

Não houve diferença significativa entre os extratos de L. leucocephala e $H$. dulcis e a testemunha para os parâmetros diâmetro do caule e número de folhas. Foi também observado que durante o período das avaliações (novembro a abril) não houve diferença significativa a 1\% de probabilidade entre os tratamentos e o tempo de experimento, indicando não haver dependência entre os efeitos dos extratos das espécies de L. leucocephala e $H$. dulcis para estas variáveis de crescimento ao longo do tempo. Amiroh e Nugrohoh (2015) estudaram o efeito alelopático de serapilheira de Eugenia Caryophillata Thunb aplicado sobre Zea Mays L. e Phaseolus Radiatus L., e tal qual o resultado observado para L. leucocephala e $H$. dulcis, verificaram que parâmetros como número de folhas e biomassa de ambas as plantas não foram afetados.

A deposição do extrato em pó das folhas de L. leucocephala e $H$. dulcis não afetou a biomassa das plantas de P. dubium (Tabela 4). 


\section{Tabela 4 - Massa seca da raiz e parte aérea de Peltophorum dubium (Spreng.) Taub. sob efeito do extrato em pó de Leucaena leucocephala (Lam) R. de Wit e Hovenia dulcis Thunberg. Cascavel-PR, 2015.}

\begin{tabular}{lcc}
\hline Tratamentos & Massa seca de raiz $(\mathrm{g})$ & Massa seca de parte aérea $(\mathrm{g})$ \\
\hline Testemunha & 14,56 & 12,43 \\
L.leucocephala & 15,42 & 14,11 \\
H. dulcis & 13,94 & 13,87 \\
CV $(\%)$ & 11,27 & 6,50 \\
\hline
\end{tabular}

Na literatura também são observadas outras espécies exóticas invasoras que não promoveram efeitos alelopáticos sobre a biomassa de plantas nativas. Mudrák e Frouz (2012) verificaram que a serapilheira de Salix caprea não influenciou a biomassa das plântulas de Arrhenatherum elatius (L.) P. Beauv. EX J. Presl e C. Presl, Plantago lanceolata L. e Lotus corniculatus L. Também Poeiras e Carmo (2007), verificaram que a presença de serapilheira de Eucalyptus grandis W. Hill., não afetou o desenvolvimento de plantas de Cajanus cajan (L) Hunth. Segundo Mohler (2001), os aleloquímicos liberados de coberturas em decomposição na superfície do solo podem não difundir suficientemente rápido e profundamente no perfil do solo, o que pode reduzir os efeitos sobre o desenvolvimento das plantas.

Ahmed et al. (2008) observaram que a interferência de L. leucocephala em relação aos parâmetros de comprimento da parte aérea, comprimento da raiz e número de folhas foi tanto maior quanto maior a quantidade de serapilheira aplicada sobre as espécies receptoras Vigna unguiculata, Cicer arietinum, Cajanus cajan e Albizia procera. Também Boeni (2011) ao verificar crescimento das plântulas de Casearia sylvestris, aplicando solução com lixiviados de $H$. dulcis, verificou que estas não conseguiram se estabelecer.

Porém, os resultados referentes a $M$. bimucronata não evidenciaram efeito alelopático oriundo de extrato em pó de $L$. leucocephala e $H$. dulcis, discordando dos autores supracitados. A concentração de aleloquímicos no solo é fortemente influenciada por fatores ambientais. Fatores bióticos e abióticos podem influenciar tanto a produção de aleloquímicos por espécie doadora (a espécie a partir da qual os aleloquímicos se originam) e modificar o efeito de um aleloquímico na planta receptora. A influência de fatores como luz, disponibilidade de nutrientes, água e pesticidas pode afetar a quantidade de aleloquímicos em uma planta (REIGOSA; SÁNCHEZMOREIRAS; GONZÁLEZ, 1999; INDERJIT et al., 2011).

Estes compostos são liberados no ambiente e também removidos continuamente e/ou imobilizados, seja por volatilização ou degradação por microorganismos (ZHU; ZHANG; KEPING,2011). Componentes bióticos do ecossistema, como herbívoros, patógenos e organismos decompositores podem alterar as concentrações de produtos químicos já nos tecidos vegetais ou liberado a partir de plantas (INDERJIT et al., 2011) afetando, portanto, a resposta da planta frente aos aleloquímicos, os quais podem ser diminuídos a concentrações que não chegam a causar efeitos evidentes, o que pode ter acontecido com as espécies do presente estudo, P. dubium e $M$. bimucronata.

Também, o efeito alelopático de várias espécies de plantas, inclusive $H$. dulcis, é associado à presença de metabólitos polares, como os compostos fenólicos. Estes normalmente são encontrados em pequenas concentrações em espécies com menor longevidade foliar (NOLETO, 2010), como 
a H. dulcis, que é caracterizada como espécie decídua (SILVA, 2001). As principais transformações que ocorrem durante a decomposição do material orgânico são a perda de componentes fenólicos que podem ser reduzidos pela ação de intemperismos e microbiota na serapilheira (PORTELA et al., 2004), sendo a redução destes compostos uma justificativa para a ausência de interferência alelopática da $H$. dulcis sobre $M$. bimucronata.

Além disso, em diferentes estádios fenológicos, a composição e concentração de todos os tipos de produtos químicos, incluindo aleloquímicos, são diferentes. $\mathrm{O}$ conteúdo de mimosina, principal composto a qual é atribuída a potencialidade alelopática negativa de todos os membros do gênero Leucaena, foi quantificado por Xuan et al. (2006), os quais verificaram que folhas maduras não contêm grande quantidade de mimosina quando comparadas com outras partes da planta. Isto poderia explicar a não ocorrência de resposta alelopática na morfologia das plantas (Tabelas 1, 2, 3 e 4), visto ser a serapilheira formada pela queda de componentes senescentes da parte aérea das plantas.

\section{CONCLUSÕES}

A L. leucocephala e a $H$. dulcis não promoveram influência alelopática em nenhuma das variáveis de crescimento quando da deposição do pó de suas folhas sobre a espécie $M$. bimucronata. Para $P$. dubium, verificou-se estímulo de crescimento da variável altura quando submetidos aos tratamentos com os extratos em pó de ambas as espécies doadoras, observados nos dois meses finais de experimento.

\section{REFERÊNCIAS}

AHMED, R.; RAFIQUL HOQUE, A.M.; HOSSAIN, M.K. Allelopathic effects of Leucaena leucocephala leaf litter on some forest and agricultural crops grown in nursery. Journal of Forestry Research, v.19, p. 298-302,2008. DOI: 10.1007/s11676-008-0053-0

AMIROH, A.; NUGROHO, D.A. Allelopathy trial of clove leaf litter (Eugenia Caryophillata Thunb.) on vegetative growth of maize (Zea mays L.) and mungbean (Phaseolus radiatus L). Journal of Agriculture and Veterinary Science, v. 8, p.66-70, 2015. DOI: $10.9790 / 2380-08216670$

BELLOTTO, A.; GANDOLFI, S.; RODRIGUES, R.R. Principais iniciativas de restauração florestal na mata atlântica, apresentadas sobre a ótica da evolução dos conceitos e dos métodos aplicados. In: RODRIGUES, R.R.; BRANCALION, P.H.S.; ISERNHAGEN, I. (Org.). Pacto pela restauração da Mata Atlântica: referencial dos conceitos e ações de restauração florestal. São Paulo: LERF/ESALQ Instituto BioAtlântica, 2009. p. 11-23.

BERTALOT,M.J.A.; GUERRINI, I.A.; MENDOZA, E.; DUBOC, E.; BARREIROS, R.M.; CORREA, F.M. Retorno de nutrientes ao solo via deposição de serapilheira de quatro espécies leguminosas arbóreas na região de Botucatu - São Paulo, Brasil. Scientia Forestalis, v.65, p.219-227, 2004. 
BOENI, B.O. Riqueza, estrutura e composição de espécies arbóreas em floresta secundária invadida por Hovenia dulcis Thunb. caracterização do seu nicho de regeneração e efeitos alelopáticos. 2011. 105f. Dissertação (Mestrado em Biologia) Universidade do Vale do Rio Sinos, São Leopoldo, 2011.

BRASIL. Ministério do Meio Ambiente. Conselho Nacional do Meio Ambiente. Resolução n. 2, de 18 de março de 1994. Diário Oficial [da] República Federativa do Brasil. Brasília, DF, 18 de março de 1994. Disponível em: <www.mma.gov.br/port/conama/ res/res94/res0294.html >. Acesso em: 5 de maio de 2015.

BRASS, F.E.B. Análise de atividade alelopática de extrato aquoso de falsamurta sobre a germinação de picão-preto e caruru. Centro Científico Conhecer - Enciclopédia Biosfera, v. 5. P.1-19, 2009.

CAMPOS, J.B.; SILVEIRA FILHO, L. Floresta Estacional Semidecidual. Série ecossistemas paranaenses. 2010. Disponível em: www.meioambiente.pr.gov.br/ arquivos/File/cobf/V5_Floresta_Estacional_semidecidual.pdf. Acesso em: 27 de maio de 2013.

CARVALHO, P.E.R.Maricá-Mimosa bimucronata. Colombo, EMBRAPA.10p. 2004. (Circular técnica, 94).

DONADIO, N.M.M.; DEMATTÊ,M.E.S.P.Morfologia de frutos, sementes e plântulas de canafístula (Peltophorum dubium (spreng.) Taub.) e jacarandá-da-bama (Dalbergia nigra (ver.) fr.ar. exbentb.) - Fabaceae. Revista Brasileira de Sementes, v.22, p.64-73, 2000.

DURIGAN, G.; NOGUEIRA, J.C.B. Recomposição de matas ciliares. IF Série Registros, São Paulo, v. 4, p.1-14, 1990.

FERRETTI, A.R.; BORGES, C.R.S.; BRITEZ, R.M. Os estados da Mata Atlântica: Paraná. In: CAMPANILI, M.; PROCHNOW, M. (Org.) Mata Atlântica - uma rede pela floresta. Brasília, RMA, p. 58-76, 2006.

GENOVESI, P. Eradications of invasive alien species in Europe: a review. Biological Invasions. Bologna, v. 7, p.127-133, 2005. DOI: 10.1007/1-4020-3870-4_12

GUBERT-FILHO, F. O desflorestamento do Paraná em um século. In: SONDA, C.; TRAUCZYNSKI, S. (Eds.) Reforma Agrária e Meio Ambiente: teoria e prática no estado do Paraná. Curitiba, ITCG, p. 15-25, 2010.

GRIS, D. Riqueza e similaridade da vegetação arbórea do corredor ecológico de Santa Maria- PR. 2013. 50f. Dissertação (Mestrado em Conservação e Manejo de Recursos Naturais) - Universidade Estadual do Oeste do Paraná, Cascavel, 2012. 
HAVLIN, J.L.; BEATON, J.D.; TISDALE, S.L.; NELSON, W.L. Soil fertility and fertilizers. 7th ed. Upper Saddle River, Pearson Education, 2005. 515p.

IAPAR-INSTITUTO AGRONÔMICO DO PARANÁ. Cartas Climáticas do Paraná. Disponível em: http:/www.iapar.br/modules/conteudo/conteudo.php?conteudo=863\#. Acesso em: 28 de outubro de 2014.

INDERJIT, WARDLE, D.; KARBAN, R.; CALLAWAY, R.M. The ecosystem and evolutionary contexts of allelopathy. Trends in Ecology e Evolution, v. 26, p. 655-662, 2011. DOI: $10.1016 /$ j.tree.2011.08.003

LORENZI, H. Árvores Brasileiras: manual de identificação e cultivo de plantas arbóreas nativas do Brasil. $3^{\mathrm{a}}$ ed. Nova Odessa, Instituto Plantarum, 2000. 352p.

LORENZI, H. Árvores brasileiras: manual de identificação e cultivo de plantas arbóreas nativas do Brasil. $5^{\mathrm{a}}$ ed. Nova Odessa: Instituto Plantarum, 2008. 368p.

MOHLER, C.L. (2001) Weed life history: identifying vulnerabilities. In: MATT, L.; MOHLER, C. L.; STAVER, C.P. (eds) Ecological management of agricultural weeds. Cambridge, Cambridge University Press. p. 40-98.

MORETTO, S.P. Uma crescente ameaça conservação da biodiversidade: O reflorestamento com espécies exóticas em Lages. Rev. Bras. de Agroecologia, v. 4, p.1649-1652, 2009.

MUDRÁK, O.; FROUZ, J. (2012) Allelopathic effect of Salix caprea litter on late successional plants at different substrates of post-mining sites: pot experiment studies. Botany, v. 90, p. 311-318, 2012.DOI: 10.1139/b2012-005

NOLETO, L.G. Longevidade foliar, compostos fenólicos e nitrogenados em árvores e lianas de um fragmento de Cerrado na Estação Experimental de Itirapina, São Paulo. 2010.108f. Tese (Doutorado em Biologia Vegetal) - Universidade Estadual de Campinas, Campinas, 2010.

OLADOYE, A.O.; OLA-ADAMS, B.A.; ADEDIRE, M.O.; AGBOOLA, D.A. Nutrient dynamics and litter decomposition in Leucaena leucocephala (Lam.) de Wit plantation in the Nigerian Derived Savanna. West African Journal of Applied Ecology, v. 13, p.96-103, 2008.DOI: 10.4314/wajae.v13i1.40587

OLIVEIRA, F.A.; CAMPOS, M.S.; OLIVEIRA, M.K.T.; MEDEIROS, J.F.; SILVA, O.M.P. Interação entre salinidade e fontes de nitrogênio no desenvolvimento inicial da cultura do girassol. Revista Brasileira de Ciências Agrárias, v.5, p.479-484, 2010. DOI:10.5039/agraria.v5i4a806

PAREPA,M.; SCHAFFNER,U.; BOSSDORF,O. Sources and modes of action of invasive knotweed allelopathy: the effects of leaf litter and trained soil on the germination and growth of native plants. NeoBiota, v.13, p.15-30, 2012. DOI: 10.3897/neobiota.13.3039 
PARVIN, R.; SHAPLA, T.L.; AMIN, M.H.A. Effects of leafs and Leucaena leucocephala different tree depth soil on the allelopathy of agricultural crops. J. Innov. Dev. Strategy, v. 5, p. 61-69, 2011.

PIROLI, E.L.; CUSTÓDIO, C.C.; ROCHA, M.R.V.; UDENAL, J.L. Germinação de sementes de canafístula Peltophorum dubium (spreng.) taub. tratadas para superação da dormência. Colloquium Agrariae, v. 1, p.13-18, 2005.

POEIRAS, L.M.; CARMO, F.M.S.A. Serapilheira de Eucalyptus grandis W. HILL. influencia o desenvolvimento das plantas e anodulação radicular em algumas leguminosas. In: VIII Congresso de Ecologia do Brasil, Caxambu. Anais, Sociedade de Ecologia do Brasil. p. 1-2, 2007.

PORTELA, L.S.; FERNANDES, M.M.; PEREIRA, M.G.; SAMPAIO, L.M.; MARTINHO, A.F. Compostos orgânicos e fauna do solo e sua relação com a decomposição da serapilheira na Flona Mário Xavier -RJ. Agronomia, v. 38, p.79-83, 2004.

PRATES, H.T.; PIRES, N.M.; PEREIRA FILHO, I.A. Controle de plantas daninhas na cultura do milho utilizando leucena (Leucaena leucocephala (Lam.) de Wit). Revista Brasileira de Milho e Sorgo, v.2, p.36-43, 2003.DOI: 10.18512/1980-6477

REIGOSA, M.J.; SÁNCHEZ-MOREIRAS, A.; GONZÁLEZ, L. Ecophysiological approach in allelopathy. Critical Reviews in Plant Sciences, v. 18, n.5, p. 577-608, 1999. DOI: $10.1080 / 07352689991309405$

ROSA, D.M. (2006) Potencial alelopático de Panicum maximum Jacq sobre a germinação de sementes de espécies nativas e seu controle por outras espécies vegetais. 2006. 58f. Trabalho de conclusão de curso (Graduação em Biologia) Universidade Estadual do Oeste do Paraná, Cascavel.

SCHEER, M.B. Decomposição e liberação de nutrientes da serapilheira foliar em um trecho de Floresta Ombrófila Densa Aluvial em regeneração, Guaraqueçaba (PR). Floresta, v. 38, p.253-266, 2008. DOI: 10.5380/rf.v38i2.11620

SCHUMACHER, M.V.; BRUN, E.J.; ILLANA, V.B.; DISSIUTA, S.I.; AGNE, T.L. Biomassa e nutrientes em um povoamento de Hovenia dulcis Thunb., plantado na Fepagro Florestas, Santa Maria. Ciência Florestal, v.18, p. 27-37, 2008. DOI: $10.5902 / 19805098519$

SECRETARIA DE ESTADO DE AGRICULTURA E ABASTECIMENTO - SEAB. Precipitação pluviométrica. Disponível em: www.agricultura.pr.gov.br/arquivos/File/ deral/pluvio. Acesso em: 28 de outubro de 2014.

SILVA, D.A. Comparação de características foliares de espécies lenhosas entre 
cerrado denso, cerrado sensu stricto e campo sujo na Reserva Ecológica do IBGE, Brasília (DF). 2001. 68f. Dissertação (Mestrado em Ecologia) - Universidade de Brasília, Brasília, 2001.

SONEGO, E.T.; CUZZI, G.; VILLANI A, FREDDO, A.R.; SANTOS, I.D. Extratos alelopáticos de capim Tanzânia no desenvolvimento inicial de plântulas de milho. Revista Brasileira de Tecnologia Aplicada nas Ciências Agrárias, v.5, p.61-72, 2012. DOI: 10.5777/paet.v5i2.1715

SOUZA, L.S.; VELINI, E.D.; MARTINS, D.; ROSOLEM, C.A. Efeito alelopático de capim-braquiária (Brachiaria decumbens) sobre o crescimento inicial de sete espécies de plantas cultivadas. Planta daninha, v.24, p.657-668, 2006. DOI: 10.1590/S010083582006000400006

SOS MATA ATLÂNTICA / INPE / ISA. Atlas da evolução dos remanescentes florestais e ecossistemas associados no domínio Mata Atlântica no período 1990-1995. São Paulo. SOS Mata Atlântica / INPE / ISA, 1998, 54p.

TOSCAN, M.A. Produção de serapilheira e chuva de sementes no corredor de biodiversidade Santa Maria, PR. 2013. 67f. Dissertação (Mestrado em Conservação e Manejo de Recursos Naturais) - Universidade Estadual do Oeste do Paraná, Cascavel, 2013.

TOSCAN, M. A.; TEMPONI, L.G.; GUIMARÃES, A.T.B.; CÂNDIDO-JR, J.F. Litter production and seed rain in Seasonal Semideciduous Forest fragments at different successional stages in Western Paraná, Brazil. Acta Botanica Brasílica, v.28, p.392-403, 2014. DOI: 10.1590/0102-33062014abb3344

VALAITES, P. Inventário florestal no corredor de biodiversidade Santa Maria, em Santa Terezinha de Itaipu - PR. 2011. 81f. Trabalho Conclusão de Curso (Graduação em Engenharia Ambiental) - Faculdade Dinâmica das Cataratas, Foz do Iguaçu, 2011.

XUAN,T.D.; ELZAAWELLY,A.A.; DEBA, F.; FUKUTA, M.; TAWATA, S. Mimosine in Leucaena as a potent bio-herbicide. Agron. Sustain. Dev., v.26, p.89-97, 2006. DOI: 10.1051/agro:2006001

ZENNI, R.D.; ZILLER, S.R. An overview of invasive plants in Brazil. Revista Brasileira de Botânica, v.34, p.431-446, 2011. DOI: 10.1590/S0100-84042011000300016

ZHU,X.; ZHANG,J.; KEPING,M.A. Soil biota reduce allelopathic effects of the invasive Eupatorium adenophorum, Plos One,v.6,p.1-6,2011.DOI: 10.1371/journal.pone.0025393 